\title{
History and Development of the Simulation Effectiveness Tool (SET)
}

\author{
Victoria L. Elfrink Corgi \\ The Ohio State University \\ Kim Leighton \\ Bryan LGH College of Health Sciences \\ Nancy Ryan-Wenger \\ The Ohio State University \\ Thomas J. Doyle \\ Patricia K. Ravert \\ Brigham Young University - Provo, patricia-ravert@byu.edu \\ Follow this and additional works at: https://scholarsarchive.byu.edu/facpub \\ Part of the Other Nursing Commons
}

\section{Original Publication Citation}

Elfrink Cordi, V. L., Leighton, K., Ryan-Wenger, N., Doyle, T. J., \& Ravert, P. (2012, July/August). History and development of the Simulation Effectiveness Tool (SET). Clinical Simulation in Nursing, 8(6), e199-e210.

\section{BYU ScholarsArchive Citation}

Elfrink Corgi, Victoria L.; Leighton, Kim; Ryan-Wenger, Nancy; Doyle, Thomas J.; and Ravert, Patricia K., "History and Development of the Simulation Effectiveness Tool (SET)" (2012). Faculty Publications. 5279. https://scholarsarchive.byu.edu/facpub/5279 accepted for inclusion in Faculty Publications by an authorized administrator of BYU ScholarsArchive. For more information, please contact ellen_amatangelo@byu.edu. 


\title{
History and Development of the Simulation Effectiveness Tool (SET)
}

\author{
Victoria L. Elfrink Cordi, PhD, RN ${ }^{\mathrm{a}, *}$, Kim Leighton, PhD, RN, CNE \\ Nancy Ryan-Wenger, PhD, RN, CPNP, FAAN", Thomas J. Doyle, MSN, RN ${ }^{d}$, \\ Patricia Ravert, RN, PhD \\ ${ }^{a}$ Ohio State University, Columbus, OH 43210, USA \\ ${ }^{b}$ Center for Excellence in Clinical Simulation, Bryan LGH College of Health Sciences, Lincoln, NE 68506, USA \\ ${ }^{c}$ College of Nursing, Ohio State University, and Nationwide Children's Hospital, Columbus, OH 43205, USA \\ ${ }^{d}$ Education \& Training Services, CAE Healthcare METI, Sarasota, FL 34240, USA \\ ${ }^{e}$ Brigham Young University, College of Nursing, Provo, UT 84602, USA
}

\section{KEYWORDS \\ evaluation research; \\ human patient \\ simulation; \\ nursing education; \\ simulation effectiveness}

\begin{abstract}
Background: There has been a lack of reliable and valid instruments measuring human patient simulation effectiveness reported in the literature. Two related studies addressing this concern are described.

Methods: A multi-phased pilot investigation at a single nursing program $(\mathrm{N}=161)$ and a follow-up multi-site national study $(\mathrm{N}=645)$ evaluated the reliability of the Simulation Effectiveness Tool (SET) as a measure of the effectiveness of a simulated clinical experience (SCE).

Results: Findings from the pilot study resulted in a revision of the original 20 -item evaluation tool to a 13-item 3-point ordinal scale instrument. Two subscales, "confidence" and "learning" were noted with Chronbach's alpha of .88 (confidence) and .87 (learning).

Conclusions: The calculated Chronbach's alpha (.93) from the multi-site investigation indicated that the 13-item SET is a reliable instrument and shows promise for measuring simulation effectiveness.

Cite this article:

Elfrink Cordi, V. L., Leighton, K., Ryan-Wenger, N., Doyle, T. J., \& Ravert, P. (2012, July/August). History and development of the Simulation Effectiveness Tool (SET). Clinical Simulation in Nursing, 8(6), e199-e210. doi:10.1016/j.ecns.2011.12.001.

(C) 2012 International Nursing Association for Clinical Simulation and Learning. Published by Elsevier Inc. All rights reserved.
\end{abstract}

Partial funding for this study was provided by CAE Healthcare METI, Sarasota Florida.

* Corresponding author: elfrink.7@osu.edu (V. L. Elfrink Cordi).

\section{Introduction and Background}

The United States is experiencing a nurse shortage that is expected to intensify as the population ages. By 2020, the nation will be short 345,000 nurses (Auerbach, Buerhaus, \& Staiger, 2007). Thus, there is a great need to educate future nurses to fill this growing gap. Despite a growth in 
the number of nursing programs, educators are being challenged to find quality clinical experiences for the increasing number of students. A strategy for addressing these concerns is high-fidelity human patient simulation. Experts argue that because simulation promotes clinical learning while not jeopard-

Key Points

- While there is a clear need for simulation been a lack of reliable and valid instruments to measure its effectiveness.

- The SET shows promise as a reliable instrument for its total score and for the "confidence" and "learning" subscale scores.

- As researchers begin to closely examine the state of simulation knowledge, they are describing the need for studies that focus on distinct evaluation needs. research, there has simulation effectiveness

izing patient safety, efforts should be made to integrate simulated learning experiences into the curriculum (Jeffries, 2005; Nehring, Lashley, \& Ellis, 2002).

The use of simulation is growing in nursing education; however, the expansion of its use has largely preceded research on pedagogy of learner experience (Seropian, Brown, \& Gavilanes, 2004). While there is a clear need for simulation research, there has been a lack of reliable and valid instruments to measure its effectiveness (Kardong-Edgren, Adamson, \& Fitzgerald, 2010). Further, the high cost of high-fidelity human patient simulation in technical and human resources has prompted administrators and faculty alike to contemplate its value (McCausland, Curran, \& Cataldi, 2004; Nehring, 2010). In response to these concerns, researchers are studying systematic assessment methods and developing standardized tools for evaluating human patient simulation (Jeffries, \& Rizzolo, 2006; Morgan, Pittini, Regeher, Marrs \& Haley, 2007; Todd, Manz, Hawkins, Parsons, \& Hercinger, 2008). This article is the first of a twopart series that describes a multiphased, large-scale, and multisite study to evaluate simulation effectiveness. The purpose of this article is to illustrate a systematic effort to establish reliability and validity of a previously developed tool so that it could then be used to evaluate the effectiveness of simulated clinical experiences (SCEs).

\section{Review of Literature}

\section{The Research Gap}

Although the body of knowledge surrounding high-fidelity human patient simulation in the nursing curriculum is growing, a gap remains between published research and simulation practice. In Nehring (2010) only 26 published studies involving patient simulation and nursing education were identified. The studies were divided into four categories, "simulation as an adjunct to traditional teaching, as a means of assessing competence, as a substitute for judgment, and as a method of teaching" (p. 29). Citing the need for studies that support the efficacy of high-fidelity patient simulation in nursing education, Nehring also noted that the current research is inconclusive. Many of the published studies have had small sample sizes and used instruments that have not been subjected to validity or reliability testing.

Kardong-Edgren et al. (2010) also conducted a review of published evaluation instruments for human patient simulation to determine the effectiveness of human patient simulation in nursing education. Citing the findings from two major simulation journals in nurse and medical education, the authors provided information on 22 simulation evaluation tools. Most of the identified tools did not report reliability and validity statistics.

Lapkin, Levett-Jones, Bellchambers, and Fernandez (2010) conducted a literature review to identify studies examining the effectiveness of simulation in teaching clinical reasoning skills. Limiting their search to studies that used randomized samples with undergraduate nursing students, Lapkin et al. concluded that there was a lack of evidence to support the effectiveness of using high-fidelity simulation in teaching clinical reasoning skills to undergraduate nursing students.

The need for future studies is addressed in each article through similar, but somewhat distinct, suggestions. Nehring (2010) called for studies that not only examine whether simulation helps to increase student knowledge and skill, but also explore nurse educator competencies. Kardong-Edgren et al. (2010) suggested the need for studies that measure performance in the psychomotor, cognitive, and affective learning domains. Lapkin et al. (2010) identified the need for studies to determine the effectiveness of simulation as a strategy to improve clinical reasoning. Each of these articles reached the conclusion that there is a need for standardized instruments that have been psychometrically tested in multiple settings with different types of participants.

\section{Reliability and Validity in Instrument Development}

When a multi-item instrument is developed, its intent is to measure attributes that represent one or more constructs that are under study. It is also vital that the instrument possess psychometric characteristics that contribute to validity and reliability of the tool in order to ensure that the tool is measuring what it purports to (validity) and that this happens consistently each time the instrument is administered (reliability). It is important to consider that a multi-item instrument serves as a proxy measure of the construct of interest (Nunnally \& Bernstein, 1994). The tool in this investigation was a multi-item instrument designed to measure simulation effectiveness, or how effective the simulated learning experience is in meeting students' learning needs. 
The rationale for performing reliability tests on newly developed tools is based on the premise that there is an inherent degree of error (random error) in the administration of any measurement instrument. Reliability reflects the extent to which an instrument is free of random error (Bannigan \& Watson, 2009). The instrument should have similar results each time it is used under similar conditions with the same participants. "The less variation an instrument produces in repeated measurements of an attribute, the higher its reliability" (Polit \& Hungler, 1995, p. 347).

Reliability can be determined in different ways. Among the most common methods are (a) test-retest, which measures the stability of the scale over time; (b) interitem, which calculates the internal consistency of the items chosen to measure the attributes of the construct; and (c) inter-rater, which gauges observers' consistency when choosing responses on the scale (Polit \& Hungler, 1995). Regardless of the method used, reliability calculations are estimations of reliability. Reliability is a prerequisite for validity (Mitchell, \& Jolley, 2010).

Carmines and Zellar (1979) define validity as "the extent to which any measuring instrument measures what it is supposed to measure" (p. 17). However, validity does not strictly validate a test; it instead focuses on the meaning and interpretation of the instrument in order to ensure it measures what it intends to (Bannigan \& Watson, 2009; Carmines \& Zellar, 1979). Validity can also be understood in different ways, most commonly as (a) face validity, whereby the instrument and its items appear to correlate with what is being measured; (b) content validity, which asks whether there enough items to sufficiently represent the idea of the construct, a question typically answered by a group of experts; (c) criterion-related validity, which compares items against those of another scale with known validity, a task difficult to do with the paucity of measurement tools available in simulation; and (d) construct validity, which asks whether the items on the tool really measure the construct being studied, an endeavor requiring statistical analysis and often the judgment of the researcher (Polit \& Hungler, 1995; Trochim, 2006).

Bannigan and Watson (2009) discussed the procedures for assessing the different types of validity. Face validity may use participants or expert reviewers to consider the acceptability of an instrument; thus it does not use statistical methods. Content validity may also involve an expert panel for determining whether an instrument has included the relevant items while excluding irrelevant items. The procedures for determining content validity most often do not use formal statistical measures. Criterion validity, which compares the instrument items with an established criterion measure or some form of a gold standard, and construct validity, which compares the instrument to a theoretical construct, often use both qualitative and statistical procedures.

The characteristics of a psychometric instrument can be further described using the domain sampling model and classical measurement theory. The domain sampling model postulates that for every construct there exists a domain of an infinite number of homogeneous items. An instrument consists of a sample of those items. In this context, reliability reflects the homogeneity of an instrument, defined as "the extent to which the items share a common variance" (Nunnally \& Bernstein, 1994, p. 229). In SPSS output, the standardized Cronbach's alpha coefficient represents homogeneity reliability. When scores on an instrument are used to make decisions about groups, reliability correlations of approximately 0.80 are acceptable (Gliem \& Gliem, 2003). Reliability requires that each item correlates at .30 with at least one other item, and to avoid redundancy, should not share more than .80 variance with another item.

In classical measurement theory, a true score is the average score on an instrument administered multiple times (Trochim, 2006). The standard error of measurement (SEM) can also be used to estimate the true score and measurement error from only one administration of an instrument. A SEM smaller than the standard deviation of the total score increases the likelihood that observed scores represent true scores. The mean is a good indicator of the distribution of scores, if the SEM is less than one half of the mean of the total scores (Nunnally \& Bernstein, 1994).

Published simulation research instruments to date remain largely untested for their reliability and validity. There are some notable exceptions (Jeffries, 2005; Todd et al., 2008), and simulation research instruments are evolving in their sophistication. However, much remains to be done in developing standardized instruments that adhere to rigorous psychometric principles.

\section{Method}

\section{Initial Tool Development}

The initial tool development was linked to the creation of the Medical Education Technologies Incorporated $\left(\mathrm{METI}^{\circledR}\right)$ standardized simulation program for nursing education, entitled the Program for Nursing Curriculum Integration (PNCI). The PNCI consists of a series of evidence-based SCEs, a "roadmap" for SCE integration into the nursing curriculum, and recommendations for instructional documentation. Included in this commercial package was an evaluation tool designed to evaluate students' perceptions about their simulation experiences. More than 100 nurse faculty experts in simulation from seven schools of nursing were involved in the development of the PNCI. Evaluation tools from five of the participating programs and one from the (nonparticipating) school of the second author were used in the development of the original, 20-item evaluation instrument, which was later dubbed the Simulation Effectiveness Tool (SET).

The original evaluation instrument was crafted from the "homegrown" evaluation tools used at the programs noted above. None of the tools had been tested for reliability or 
validity, but each tool represented the concepts that were seen as important to evaluate the effectiveness of an SCE. Using a content analysis method, the second author of this article constructed an evaluation tool that represented the common themes found in each program's instrument. Three concepts were present: (a) learning (the skills or knowledge gained as a result of the SCE), (b) confidence (the self-belief in increased skill or knowledge as a result of the SCE), and (c) satisfaction attitudes (approval of the SCE as an education strategy). These concepts were translated into a 5-point Likert-type scale for the initial METI evaluation tool (see Figure 1). The final version of the original, 20-item tool was reviewed and agreed upon by faculty from each of the seven PNCI-contributing nursing programs.

The concepts of learning, self-confidence, and satisfaction attitudes are widely viewed as constructs that describe simulation effectiveness. For example, Jeffries and McNelis (2010) noted that evaluation as it relates to SCEs, "must consider the relationship between the simulation ... and the desired outcomes" (p. 406). They further explained that outcomes include knowledge, skills, critical thinking, learner satisfaction, and self-confidence. Others (Feingold, Calaluce, \& Kallen, 2004; Scherer, Bruce, \& Runkawatt, 2007; Schoening, Sittner, \& Todd, 2006) have also included the measurement of these concepts in their simulation evaluation research.

Although the original evaluation instrument was disseminated with the PNCI materials, it had not been widely used, nor had it been evaluated for reliability and validity. The Ohio State University College of Nursing (OSUCON) obtained permission from METI to evaluate the reliability of the instrument and to revise the tool as necessary.

\section{OSU Pilot Study}

The OSU pilot study was multiphased. The initial investigation examined the validity of the original, 20-item evaluation tool with a convenience sample of OSUCON prelicensure nursing students. Based on our findings and further discussions with simulation faculty experts, we revised the tool to a 3-point ordinal scale with 13 items and then analyzed our data further with a subset of our earlier sample $(N=75)$. Both study phases are described in detail.

\section{Psychometric Evaluation of the 20-Item Original Tool}

The initial testing of the METI evaluation instrument used a convenience sample of 200 prelicensure sophomore, junior, and senior nursing students enrolled in a medicalsurgical nursing foundations, nursing care of adults, highacuity, or nursing care of child-bearing families course at the OSUCON. During the term, students from each course participated in one or more simulations that were based on the learning objectives for the course. Participants each completed a paper version of the original METI evaluation instrument immediately after their last simulation clinical experience for the term. Data were transcribed from the paper forms directly into SPSS.

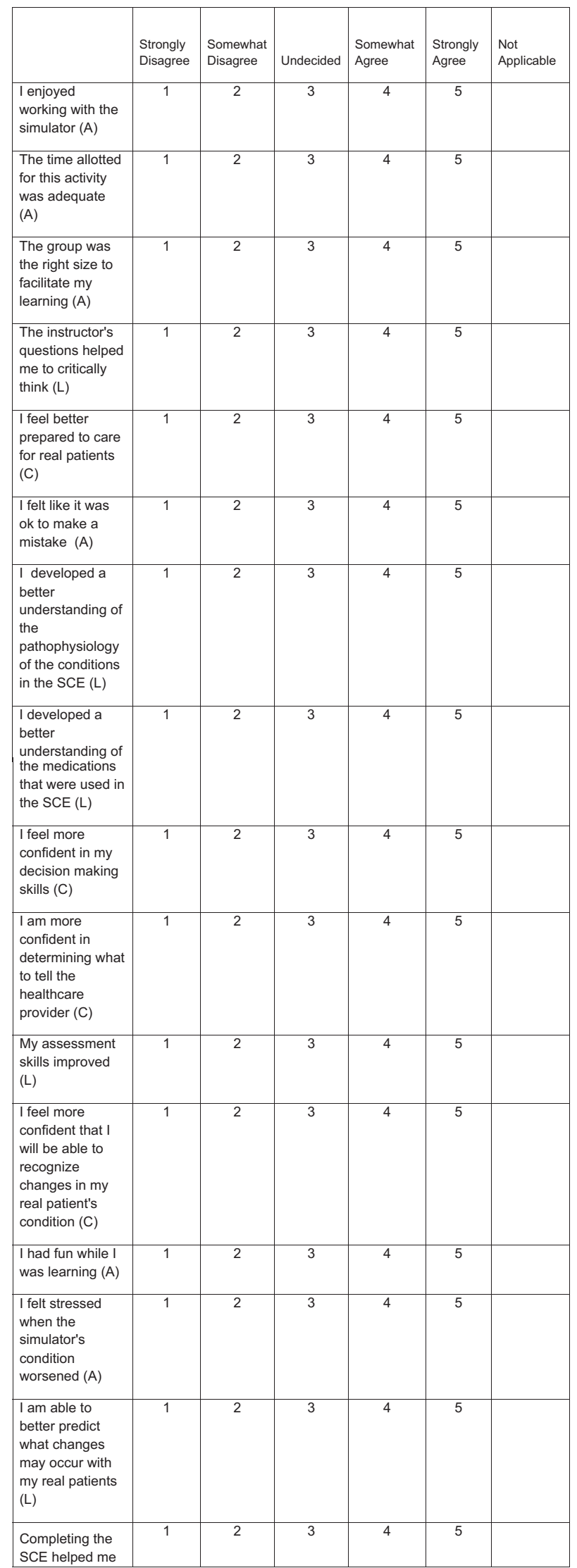

Figure 1 Original CAE Healthcare METI Evaluation Tool. 


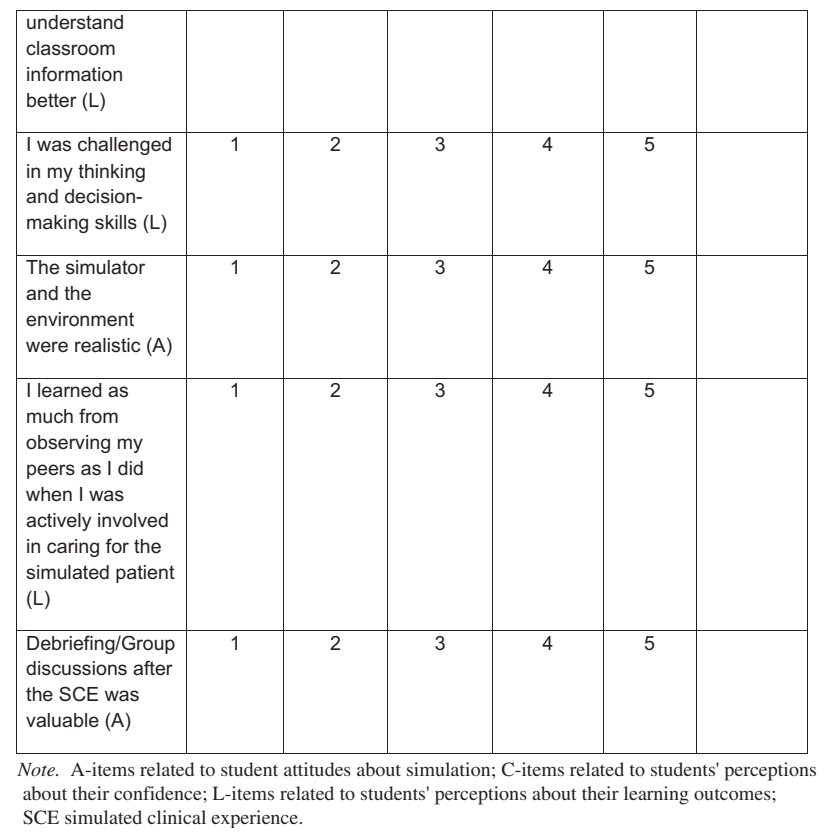

Figure 1 (continued).

Participants responded by using the original tool, which included a Likert-type scale of five responses: $5=$ Strongly agree, $4=$ Somewhat agree, $3=$ Undecided, $2=$ Somewhat disagree, 1 = Strongly disagree, and one non-scored item, Not applicable. The five Likert-type type scale items were given numerical values for statistical evaluation. There were 39 participants from the initial sample with NA responses. The NA choices were treated as missing or no data and were omitted from the total item count, leaving responses from 161 participants. All statistical analyses were based on the responses from the participants who responded using the 5-point Likert-type scale.

A principal components factor analysis of the 20 items revealed four significant factors with eigenvalues ranging from 8.49 to 1.08. All items loaded on Factor 1 with correlations from 0.32 to 0.83 , indicating that a total score would serve as a proxy for the construct of simulation effectiveness. There was little similarity among the items that loaded higher on Factors 2 (confidence), 3 (learning), and 4 (attitudes) than on Factor 1; therefore, no meaningful subscales were evident.

\section{Development and Psychometric Evaluation of the 13-Item SET}

The 20-item original METI evaluation instrument had adequate reliability, but the statistical analysis indicated some items were problematic for various reasons. Specifically, some item-total correlations had little contribution to the total score. Examples of low item-total correlations included "Time allotted was adequate" and "Group size was right." Another item, "I felt stressed when the simulator's condition worsened," was especially problematic. The correlations for this item were all negative and had only a .28 total item correlation. Additionally, this was the only item that required reverse scoring, which could be cumbersome to the users of the instrument. Another interitem correlation indicated a redundancy of the items "I had fun while I was learning" and "I enjoyed working with the simulator."

Construct validation requires judgment on the part of the researcher, along with statistical analysis (Polit and Beck, 2008); therefore, findings from the statistical analysis were not the sole determinants of which items to keep. Specifically, although we found that some of the "attitude" items, such as "The simulator and the environment were realistic," correlated moderately high with the total items, this item did not measure any type of student outcome beyond student satisfaction. We held further discussions with the original instrument developers and received comments from the OSU simulation faculty and then made a post hoc decision to focus the instrument on the student outcomes for learning and confidence and delete the items related to student attitudes about simulation. Post hoc determination of the concepts was appropriate, considering the instrument had already been developed when the additional testing was undertaken. We debated about the inclusion of one item, "I had fun while learning," which had the word learning in the stem. However, we ultimately decided to delete the item as we determined that it was conceptually intended to measure an attitude toward the SCE and not a student outcome, resulting in a revised of scale with 13 items (see Table 1).

The revised scale had a Cronbach's alpha for the overall survey of 0.91, with an SEM of 1.56. Additionally, a principal components factor analysis indicated that two subscales were now present, which were named Learning and Confidence. The concepts were operationally defined by the research team as (a) learning: the student's self-assessment of the knowledge and skills gained from the simulation experience, and (b) confidence: the students' self-assessment of their abilities and attributes gained from the simulation experience.

The Learning subscale consists of eight items with a Cronbach's alpha of .87. The Confidence subscale contains five items with a Cronbach's alpha of .84 .

Yet another revision to the original METI tool centered on changing the ratings from a 5-point to a 3-point ordinal scale. Our initial pilot findings suggested that the participants' responses were clustering in the undecided and somewhat agree categories and that the tool was not discriminating opinions clearly. We excluded participants who initially rated the instrument items as a 3 (undecided) and recalculated the Cronbach's alpha and SEM using a sample size of 75 . This study found no significant differences in the reliability of the 5-point versus the 3-point scale, nor did the 5-point scale yield greater stability or the capacity to distinguish among the subscales. As the tool was intended to measure simulation effectiveness by differentiating items perceived as effective from those that were not, we decided to reduce the scale points in order to force the choices of effective or 
Table 1 Simulation Effectiveness Tool (SET) Items, Inter-item Correlations, and Item-to-Total Correlations

\begin{tabular}{|c|c|c|c|c|c|c|}
\hline Original SET Items (20) & $\begin{array}{l}\text { Inter-item Correlations } \\
(\% \geq .30)\end{array}$ & $\begin{array}{l}\text { Item-to-Total } \\
\text { Correlation }\end{array}$ & Category & $\begin{array}{l}\text { Revised SET } \\
\text { Items (13) }\end{array}$ & $\begin{array}{l}\text { Inter-item Correlations } \\
(\% \geq 0.30)\end{array}$ & $\begin{array}{l}\text { Item-to-Total } \\
\text { Correlation }\end{array}$ \\
\hline I enjoyed working with the simulator. & $.10-.68(65)$ & .66 & Attitude & $x$ & & \\
\hline The time allotted for this activity was adequate. & $.07-.33(10)$ & .32 & Attitude & $x$ & & \\
\hline The group was the right size to facilitate my learning. & $.06-.34(10)$ & .31 & Attitude & $x$ & & \\
\hline The instructor's questions helped me to critically think. & $.18-.63(80)$ & .61 & Learning & $\sqrt{ }$ & $.13-0.55(77 \%)$ & .49 \\
\hline I feel better prepared to care for real patients. & $.21-.66(75)$ & .76 & Confidence & $\sqrt{ }$ & $.16-0.62(77 \%)$ & .61 \\
\hline I felt like it was ok to make a mistake. & $-.01-.44(70)$ & .45 & Confidence & $x$ & & \\
\hline $\begin{array}{l}\text { I developed a better understanding of the pathophysiology } \\
\text { of the conditions in the simulation. }\end{array}$ & $.06-.58(60)$ & .52 & Learning & $\sqrt{ }$ & $.23-0.58(69 \%)$ & .59 \\
\hline $\begin{array}{l}\text { I developed a better understanding of the medications that } \\
\text { were in the simulation. }\end{array}$ & $.08-.66(75)$ & .59 & Learning & $\sqrt{ }$ & $.21-0.70(77 \%)$ & .72 \\
\hline I feel more confident in my decision-making skills. & $.20-.66(75)$ & .78 & Confidence & $\sqrt{ }$ & $.20-0.71(85 \%)$ & .75 \\
\hline $\begin{array}{l}\text { I am more confident in determining what to tell the } \\
\text { healthcare provider. }\end{array}$ & $.19-.56(75)$ & .69 & Confidence & $\sqrt{ }$ & $.27-0.71(85 \%)$ & .67 \\
\hline My assessment skills improved. & $.23-.68(75)$ & .76 & Learning & $\sqrt{ }$ & $.28-0.58(85 \%)$ & .72 \\
\hline $\begin{array}{l}\text { I feel more confident that I will be able to recognize changes } \\
\text { in my real patient's condition. }\end{array}$ & $.15-.68(70)$ & .74 & Confidence & $\sqrt{ }$ & $.25-0.64(85 \%)$ & .70 \\
\hline I had fun while I was learning. & $.14-.68(65)$ & .62 & Attitude & $x$ & & \\
\hline I felt stressed when the simulator's condition worsened. & $-.01-.33(5)$ & .28 & Attitude & $x$ & & \\
\hline $\begin{array}{l}\text { I am able to better predict what changes may occur with } \\
\text { my real patients. }\end{array}$ & $.20-.61(75)$ & .71 & Learning & $\sqrt{ }$ & $.23-0.56(85 \%)$ & .60 \\
\hline $\begin{array}{l}\text { Completing the simulation helped me understand classroom } \\
\text { information better. }\end{array}$ & $.16-.62(75)$ & .66 & Learning & $\sqrt{ }$ & $.25-0.58(85 \%)$ & .70 \\
\hline I was challenged in my thinking and decision-making skills. & $.18-.63(80)$ & .71 & Learning & $\sqrt{ }$ & $.19-0.62(77 \%)$ & .68 \\
\hline The simulator and the environment were realistic. & $.18-.57(70)$ & .63 & Attitude & $x$ & & \\
\hline $\begin{array}{l}\text { I learned as much from observing my peers as I did when } \\
\text { I was actively involved in caring for the simulated patient. }\end{array}$ & $.05-.51(10)$ & .34 & Learning & $\sqrt{ }$ & $.13-0.40(31 \%)$ & .35 \\
\hline Debriefing and group discussion were valuable. & $.12-.51(50)$ & .47 & Learning & $\sqrt{ }$ & $.20-0.42(46 \%)$ & .45 \\
\hline
\end{tabular}


not effective. As a result, we changed the rating scale from a 5-point Likert-type scale to a 3-point ordinal scale.

A comparison of the original METI 5-point, 20-item evaluation instrument and the revised 3-point, 13-item instrument is provided in Table 2. In 2009, the 13-item survey was renamed the SET and was published in the revised PNCI (see Figure 2).

\section{Multisite Reliability Testing of the SET}

In 2009, METI requested further investigation of the SET's reliability with a multisite population. A convenience sample of participants from six nursing programs was used. Five of the programs had faculty who had assisted in developing the original, 20-item METI evaluation instrument. The programs represented the Midwestern, Southern, Southwestern, and Western regions of the country and are labeled in Table 3 according to their number of participants and other demographics. A total of 23 participants (4\%) were at a postbaccalaureate level, and the remaining 622 participants $(96 \%)$ were prelicensure students representing several courses at all course levels. There were 599 female participants (93\%) and 46 male participants (7\%). One private baccalaureate/graduate program (No. 1 in Table 3) had the most participants $(N=261)$, while the public associate degree program (No. 6) had the fewest $(N=6)$. In all, 34 of the participants $(5 \%)$ participated in the study in more than one course (see Table 3).

A coprincipal investigator at each institution recruited students there for the study. The only criterion for inclusion was that the student had to have participated in one or more high-fidelity human patient simulations during the 2009 winter, spring, or summer terms. The simulation scenarios varied widely and were based on the learning objectives for each course at each institution.

The principal investigator obtained institutional review board approval at her site, and then the coprincipals each sought institutional review board approval at their institutions. A letter requesting voluntary participation in the study was provided to potential participants. This letter described the study goals and requested that the participant complete the study instrument after the simulation. Data collection consisted of students' completing an electronic version of the SET using Checkbox Survey software. Students from each program were provided a link to the SET electronic survey, located on the server at the OSUCON. Students completed the surveys within 24 hours of their final simulation for the quarter or semester.

Data from the electronic surveys were directly exported to MicroSoft Excel and then imported into SPSS software, Version 17 . SET reliability was analyzed by calculation of Cronbach's alpha coefficients, item-total correlations, item-item correlations, and SEM for the SET and the Learning and Confidence subscales.

\section{Results}

The total Cronbach's alpha reliability of the SET was .93, a finding that was similar to the OSUCON pilot study (.90). The item analysis indicated that each of the items of the

\begin{tabular}{|c|c|c|}
\hline Statistics & Original 20 SET Items $(N=161)$ & Revised 13 SET Items $(N=75)$ \\
\hline Scale & $\begin{array}{l}1=\text { strongly disagree } \\
2=\text { disagree } \\
3=\text { undecided } \\
4=\text { agree } \\
5=\text { strongly agree }\end{array}$ & $\begin{array}{l}0=\text { do not agree } \\
1=\text { somewhat agree } \\
2=\text { strongly agree }\end{array}$ \\
\hline \multicolumn{3}{|l|}{ Total scale scores } \\
\hline $\begin{array}{l}\text { Minimum-maximum } \\
M(S D)\end{array}$ & $\begin{array}{l}33 \text { to } 100 \\
79.6(11.9)\end{array}$ & $\begin{array}{l}3 \text { to } 26 \\
19(5.2)\end{array}$ \\
\hline \multicolumn{3}{|l|}{ Item scores } \\
\hline $\begin{array}{l}\text { Minimum-maximum } \\
M(S D)\end{array}$ & $\begin{array}{l}3.24 \text { to } 4.64 \\
3.98(.34)\end{array}$ & $\begin{array}{l}1.20 \text { to } 1.83 \\
1.46(.18)\end{array}$ \\
\hline \multicolumn{3}{|l|}{ Item variances } \\
\hline $\begin{array}{l}\text { Minimum-maximum } \\
M(S D)\end{array}$ & $\begin{array}{l}.49 \text { to } 1.47 \\
.92(.27)\end{array}$ & $\begin{array}{l}.17 \text { to } .43 \\
.34(.08)\end{array}$ \\
\hline \multicolumn{3}{|l|}{ Item-to-item correlations } \\
\hline $\begin{array}{l}\text { Minimum-maximum } \\
M(S D)\end{array}$ & $\begin{array}{l}-.01 \text { to } .72 \\
.37(.16)\end{array}$ & $\begin{array}{l}.13 \text { to } .71 \\
.43(.13)\end{array}$ \\
\hline \multicolumn{3}{|l|}{ Item-to-total correlations } \\
\hline $\begin{array}{l}\text { Minimum-maximum } \\
M(S D)\end{array}$ & $\begin{array}{l}.28 \text { to } .78 \\
.58(.17)\end{array}$ & $\begin{array}{l}.35 \text { to } .75 \\
.62(.12)\end{array}$ \\
\hline Cronbach's alpha reliability & $\begin{array}{l}.92 \\
332\end{array}$ & .91 \\
\hline SEM & 3.33 & 1.56 \\
\hline
\end{tabular}


Please circle the number that best reflects your opinion about your simulation experience.

\begin{tabular}{|l|c|c|c|}
\hline & $\begin{array}{l}\text { Do Not } \\
\text { Agree }\end{array}$ & $\begin{array}{l}\text { Somewhat } \\
\text { Agree }\end{array}$ & $\begin{array}{l}\text { Strongly } \\
\text { Agree }\end{array}$ \\
\hline The instructor's questions helped me to critically think (L) & 0 & 1 & 2 \\
\hline I feel better prepared to care for real patients (C) & 0 & 1 & 2 \\
\hline $\begin{array}{l}\text { I developed a better understanding of the pathophysiology } \\
\text { of the conditions in the SCE (L) }\end{array}$ & 0 & 1 & 2 \\
\hline $\begin{array}{l}\text { I developed a better understanding of the medications that } \\
\text { were in the SCE (L) }\end{array}$ & 0 & 1 & 2 \\
\hline I feel more confident in my decision making skills (C) & 0 & 1 & 2 \\
\hline $\begin{array}{l}\text { I am more confident in determining what to tell the } \\
\text { healthcare provider (C) }\end{array}$ & 0 & 1 & 2 \\
\hline My assessment skills improved (L) & 0 & 1 & 2 \\
\hline $\begin{array}{l}\text { I feel more confident that I will be able to recognize changes } \\
\text { in my real patient's condition (C) }\end{array}$ & 0 & 1 & 2 \\
\hline $\begin{array}{l}\text { I am able to better predict what changes may occur with my } \\
\text { real patients (C) }\end{array}$ & 0 & 1 & 2 \\
\hline $\begin{array}{l}\text { Completing the SCE helped me understand classroom } \\
\text { information better (L) }\end{array}$ & 0 & 1 & 2 \\
\hline $\begin{array}{l}\text { I was challenged in my thinking and decision-making skills } \\
\text { (L) }\end{array}$ & 0 & 1 & 2 \\
\hline $\begin{array}{l}\text { I learned as much from observing my peers as I did when I } \\
\text { was actively involved in caring for the simulated patient (L) }\end{array}$ & 0 & 1 & 2 \\
\hline Debriefing and group discussion were valuable (L) & 0 & 1 & 2 \\
\hline
\end{tabular}

Figure 2 Simulation Effectiveness Tool (subscales identified).

SET was relevant and that there was little difference in the items' contribution to the entire SET score (see Table 4).

The Confidence subscale of the SET with its five items had a calculated reliability of .88. This finding was similar to the findings of the OSUCON pilot study (.84). Although there were some differences in the confidence item correlations, ranging from moderate (.68 for "I feel better prepared in determining what to tell the health care provider") to high (.74, for "I feel more confidence in my decision-making skills") there were no significant differences in the item correlations and their contribution to the Confidence subscale. There were similar findings with the eight-item Learning subscale. The calculated reliability was .87 , a finding that was similar to the OSUCON pilot study (.87). The differences in the item correlations, ranging from moderate (.56, "I learned as much from observing my peers as I did when I was actively involved in caring for the simulated patient") to high (.70, "I was challenged in my thinking and decision-making skills") were not significantly different in their contribution to the Learning subscale (see Table 5).

The findings indicate that the SET meets the acceptable criterion (.80) for reliability for its total simulation effectiveness score and for the Confidence and Learning subscale scores. Further, the item analysis indicates that there is a high total correlation among the 13 items. Finally, the findings also support earlier results that suggested that the 13 items are loading on a single factor, which was determined as simulation effectiveness; however, the Learning and Confidence subscales are also highly correlated within the total SET.

\section{Discussion}

\section{Limitations and Recommendations}

There are several limitations of this study and recommendations for further research. First, the outcome measures reported in this study used student self-reported data; participants were both the raters and the ratees of their simulation effectiveness. Data findings that are solely selfreported perceptions have the potential to be unreliable (Prion, 2008). We recommend that future studies use the SET in conjunction with multiple standardized measures to better evaluate simulation effectiveness objectively.

Further, this study is limited by its use of a convenience sample. Although the sample size was large, with varied demographics, four of the six programs had contributed to the development of the original METI PNCI and the original evaluation instrument. Additionally, the content

Table 3 Multisite Study Participant Demographics

\begin{tabular}{|c|c|c|c|c|c|c|c|c|c|}
\hline Program & $N$ & $\begin{array}{l}\text { Student } \\
\text { Level }\end{array}$ & $N$ & $\begin{array}{l}\text { Work } \\
\text { Experience school }\end{array}$ & $N$ & $\begin{array}{l}\text { Age } \\
\text { Range }\end{array}$ & $N$ & Course Type & $N$ \\
\hline PV BSN \& GRAD 1 & 261 & Post-bac & 23 & LPN/LVN & 7 & $17-23$ & 455 & Assessment & 26 \\
\hline PB BSN 2 & 148 & Year 1 & 23 & None & 279 & $24-30$ & 106 & $\begin{array}{l}\text { Childbearing } \\
\text { midwifery }\end{array}$ & 51 \\
\hline PV BSN 3 & 116 & Year 2 & 83 & Other health care & 66 & $31-37$ & 47 & Community & 10 \\
\hline PB BSN 4 & 102 & Year 3 & 329 & Patient care assistant & 234 & $38-44$ & 19 & Fundamentals & 30 \\
\hline PV BSN 5 & 12 & Year 4 & 187 & Personal health aide & 41 & $45-51$ & 12 & Gerontology & 3 \\
\hline \multirow[t]{7}{*}{ PB ADN 6} & 6 & & & & & & & High acuity & 194 \\
\hline & & & & & & & & Leadership & 3 \\
\hline & & & & & & & & Medical-surgical 1 & 61 \\
\hline & & & & & & & & Medical-surgical 2 & 108 \\
\hline & & & & & & & & Medical-surgical 3 & 65 \\
\hline & & & & & & & & Mental health & 33 \\
\hline & & & & & & & & Pediatrics & 61 \\
\hline Total & 645 & & & & & & & & \\
\hline
\end{tabular}

Note. $\mathrm{ADN}=$ Associate degree in nursing program; LPN/LVN = Licensed practical and licensed vocational nurse; PB BSN = Bachelor of science in nursing public program; PV BSN \& GRAD = Bachelors of science in nursing and graduate private program. 
Table 4 Simulation Effectiveness Tool Item-to-Total Statistics from Multisite Study

\begin{tabular}{|c|c|c|c|c|}
\hline SET items & $\begin{array}{l}\text { Scale Mean } \\
\text { If Item } \\
\text { Deleted }\end{array}$ & $\begin{array}{l}\text { Scale } \\
\text { Variance If } \\
\text { Item Deleted }\end{array}$ & $\begin{array}{l}\text { Corrected } \\
\text { Item-to-Total } \\
\text { Correlation }\end{array}$ & $\begin{array}{l}\text { Cronbach's } \\
\text { Alpha If } \\
\text { Item Deleted }\end{array}$ \\
\hline The instructor's questions helped me to critically think. (L) & 18.55 & 27.46 & .59 & .92 \\
\hline I feel better prepared to care for real patients. (C) & 18.74 & 25.85 & .75 & .92 \\
\hline $\begin{array}{l}\text { I developed a better understanding of the } \\
\text { pathophysiology of the conditions in the SCE. (L) }\end{array}$ & 18.81 & 26.08 & .68 & .92 \\
\hline $\begin{array}{l}\text { I developed a better understanding of the } \\
\text { medications that were in the SCE. (L) }\end{array}$ & 18.88 & 25.63 & .69 & .92 \\
\hline I feel more confident in my decision-making skills. (C) & 18.80 & 25.73 & .76 & .92 \\
\hline $\begin{array}{l}\text { I am more confident in determining what to tell } \\
\text { the health care provider. (C) }\end{array}$ & 18.77 & 26.00 & .71 & .92 \\
\hline My assessment skills improved. (L) & 18.86 & 25.92 & .68 & .92 \\
\hline $\begin{array}{l}\text { I feel more confident that I will be able to recognize } \\
\text { changes in my real patient's condition. (C) }\end{array}$ & 18.76 & 26.12 & .71 & .92 \\
\hline $\begin{array}{l}\text { I am able to better predict what changes may } \\
\text { occur with my real patients. (C) }\end{array}$ & 18.77 & 26.05 & .73 & .92 \\
\hline $\begin{array}{l}\text { Completing the SCE helped me understand } \\
\text { classroom information better. (L) }\end{array}$ & 18.74 & 26.11 & .71 & .92 \\
\hline $\begin{array}{l}\text { I was challenged in my thinking and } \\
\text { decision-making skills. (L) }\end{array}$ & 18.60 & 26.55 & .71 & .92 \\
\hline $\begin{array}{l}\text { I learned as much from observing my peers as } \\
\text { I did when I was actively involved in caring } \\
\text { for the simulated patient. (L) }\end{array}$ & 18.67 & 26.97 & .56 & .92 \\
\hline Debriefing and group discussion were valuable. $(\mathrm{L})$ & 18.58 & 27.34 & .57 & .92 \\
\hline
\end{tabular}

validity evaluation of the instrument was conducted among the faculty of these programs. Thus, there is a potential bias toward the validity of the instrument. We recommend that the revised SET be tested using criterion and construct validity methods to determine whether it is accurately measuring the concept of simulation effectiveness. Additionally, while we believe that the large size of this demographically varied sample was representative of the student nurse population and in turn contributed to the generalization of the reliability findings, the use of a random sample in future studies would better establish the tool's rigor.

Another limitation focuses on the sole use of the internal consistency (Cronbach's alpha) measure to evaluate the reliability of the instrument. Although we repeated the initial OSU pilot test with a large, multisite sample, we did not conduct a test-retest with the same sample; thus, we cannot verify the stability of the instrument. We recommend that future studies also include a test-retest design to determine the stability of the SET.

Additionally, although there are precedents for using non-Likert-type scales in measurement instruments, our decision to change the SET's 5-point Likert-type type scale to a 3-point ordinal scale has met with some initial criticism. Our decision, however, has support in the evaluation literature. Specifically, there are studies that note that for Likert-type items, reliability is generally independent of the number of scale points (Komorita \& Graham, 1965; Lissitz \& Green, 1975; Matell \& Jacoby, 1972). Another study (Johnson, Smith, \& Tucker, 1982) also used a multi-method matrix and a 5-point Likert-type scale versus the original 3point ordinal scale to examine the stability and the convergent and discriminant validity of the Job Descriptive Index. We found no significant differences in the reliability of the 5point versus the 3-point scale; however, future research may want to focus on examining the reliability and utility of a version of the SET that has a 5-point, Likert-type scale.

Finally, the SET may be limited in its ability to measure simulation effectiveness because of the deletion of the attitude items from the original, 20-item METI evaluation instrument. We based our decision about item inclusion for the SET on not only the statistical analysis, but also expert opinions regarding a conceptual notion of how the instrument could best measure effectiveness. Specifically, we used a qualitative method for seeking consensus among clinical faculty on the final items and ultimately measured simulation effectiveness using the concepts of learning and confidence as student outcomes. Jeffries and McNelis (2010) noted that simulation evaluation studies should also examine student satisfaction. In turn, while we believe that student satisfaction has already been well documented in the simulation literature, researchers may want to conduct further reliability testing of the SET with a large multisite sample and include attitude items. 
Table 5 Simulation Effectiveness Tool Confidence and Learning Subscale Item-to-Total Statistics from Multisite Study

\begin{tabular}{|c|c|c|c|c|}
\hline SET items & $\begin{array}{l}\text { Scale Mean } \\
\text { If Item } \\
\text { Deleted }\end{array}$ & $\begin{array}{l}\text { Scale } \\
\text { Variance If } \\
\text { Item Deleted }\end{array}$ & $\begin{array}{l}\text { Corrected } \\
\text { Item-to-Total } \\
\text { Correlation }\end{array}$ & $\begin{array}{l}\text { Cronbach's } \\
\text { Alpha If } \\
\text { Item Deleted }\end{array}$ \\
\hline I feel better prepared to care for real patients. (C) & 6.08 & 3.86 & .72 & .86 \\
\hline I feel more confident in my decision-making skills. (C) & 6.14 & 3.79 & .74 & .85 \\
\hline $\begin{array}{l}\text { I am more confident in determining what to tell } \\
\text { the health care provider. }(C)\end{array}$ & 6.10 & 3.91 & .67 & .87 \\
\hline $\begin{array}{l}\text { I feel more confident that I will be able to recognize } \\
\text { changes in my real patient's condition. (C) }\end{array}$ & 6.10 & 3.87 & .72 & .85 \\
\hline $\begin{array}{l}\text { I am able to better predict what changes may occur } \\
\text { with my real patients. (C) }\end{array}$ & 6.11 & 3.87 & .73 & .85 \\
\hline The instructor's questions helped me to critically think. (L) & 10.92 & 9.23 & .59 & .86 \\
\hline $\begin{array}{l}\text { I developed a better understanding of the pathophysiology } \\
\text { of the conditions in the SCE. (L) }\end{array}$ & 11.18 & 8.52 & .65 & .85 \\
\hline $\begin{array}{l}\text { I developed a better understanding of the medications } \\
\text { that were in the SCE. (L) }\end{array}$ & 11.25 & 8.30 & .65 & .85 \\
\hline My assessment skills improved. (L) & 11.22 & 8.49 & .61 & .85 \\
\hline $\begin{array}{l}\text { Completing the SCE helped me understand } \\
\text { classroom information better. (L) }\end{array}$ & 11.11 & 8.47 & .70 & .84 \\
\hline I was challenged in my thinking and decision-making skills. (L) & 10.97 & 8.74 & .70 & .85 \\
\hline $\begin{array}{l}\text { I learned as much from observing my peers as I did when } \\
\text { I was actively involved in caring for the simulated patient. (L) }\end{array}$ & 11.04 & 8.94 & .56 & .86 \\
\hline Debriefing and group discussion were valuable. $(\mathrm{L})$ & 10.95 & 9.13 & .57 & .86 \\
\hline
\end{tabular}

Note. $\mathrm{C}=$ Confidence subscale; $\mathrm{L}=$ Learning subscale; $\mathrm{SCE}=$ simulated clinical experience.

\section{Conclusions}

It has already been noted that the few published studies in nursing education have largely used untested tools (Nehring, 2010; Sanford, 2010), resulting in a potential lack of adoption and progress (Kardong-Edgren et al., 2010). Further, there are calls for investigations that move beyond the focus of student self-evaluation to studies that measure student competencies (Nehring, 2010) and clinical reasoning (Lapkin et al., 2010). Kardong-Edgren et al. (2010) have gone a step further to suggest that a moratorium on indiscriminate evaluation instruments is needed and have further described the need for the development of evaluation tools that measure learning by providing students with feedback on complex learning outcomes in the cognitive, psychomotor, and affective domains. We agree with these suggestions; however, we additionally offer that there is much about the pedagogy of simulation that remains unknown and that evaluation tools that reliably measure students' self-perceptions about their learning and self-confidence can guide faculty decisions about simulation best practices.

As researchers begin to closely examine the state of simulation knowledge, they are describing the need for studies that focus on distinct evaluation needs (Jeffries \& McNelis, 2010). Using Scriven's (1996) evaluation framework, we note the differences between formative and summative evaluation. Summative evaluation is centered on the effects of the instructional activities such as simulation and might include the assignment of a grade or the assessment of a competency. In contrast, formative evaluation uses data gathered from learners to determine how well a course, program, or form of instruction is meeting the students' needs or instructional goals. Formative evaluation, as applied to simulation, could be used to change or improve the design of educational practices connected with simulation, provide faculty with insights into what does and does not work, and provide students with an opportunity to reflect on what they are learning.

Rigorous formative evaluation studies are also needed as the dearth of reliable and valid instruments currently published in the nursing literature is not limited to summative evaluation. In a review of the literature, Dunnington (2010) found nine evaluation studies dealing with student perceptions regarding human patient simulation. Eight of the nine studies used descriptive surveys specifically designed for the study. Only one study (Childs \& Sepples, 2006) used an established instrument in the method, yet each of the nine studies was used to inform simulation design and implementation practices at their respective institutions. Simulation knowledge has not yet advanced far enough for educators to know what variables influence a student's simulation experience. For example, do educators presume that students in higher level courses have more significant learning outcomes and more confidence than students in lower level courses as a result of their simulation experience? Standardized tools that can measure simulation effectiveness and compare the findings across course levels can provide evidence to either support or refute this assumption. In this way, the use of 
a standardized tool can help to inform the best educational practices regarding simulation. We will illustrate this point in Part 2 of this study.

In conclusion, our findings indicate that the SET has internal consistency and showed promise as a reliable tool when used for this multiphased, large-scale and multisite study. While this particular study of students' selfperceptions about the effectiveness of a simulation experience provided the basis for change to the original tool and demonstrated initial worth of the instrument, further evaluation remains to be done. Reliability, in particular, will be judged further as the tool is used over time and with other types of participant groups. The findings suggest the SET could be used in future studies to inform knowledge about how to design and implement SCEs. We urge researchers, faculty, and curriculum planners to use the tool, along with other standardized measures, as part of a rigorous and systematic simulation evaluation plan.

\section{Acknowledgments}

The authors would like to acknowledge the following individuals for their administration of the study objectives at their respective organizations. Dawn Hughes, MS, RN, Assistant Professor and Educator for the Patient Simulation Lab, Mount Carmel College of Nursing, Columbus, $\mathrm{OH}$; Kimberly S. Beechler, MSN, RN, Faculty Skills Lab Coordinator, Daytona State College, Daytona Beach, FL; Catherine Bailey, PhD, RN, Associate Professor of Nursing, Texas Woman's University, Dallas, TX; and Judy Johnson-Russell, Ed.D, RN, CAE Healthcare METI Adjunct Clinical Educator, Sarasota, FL.

\section{References}

Auerbach, D., Buerhaus, P., \& Staiger, D. (2007). Better late than never: Workforce supply implications of later entry into nursing. Health Affairs, 26(1), 178-185.

Bannigan, K., \& Watson, R. (2009). Reliability and validity in a nutshell. Journal of Clinical Nursing, 18, 3237-3243.

Carmines, E. G., \& Zellar, R. A. (1979). Reliability and validity assessment. Beverly Hills, CA: Sage.

Childs, J., \& Sepples, S. (2006). Clinical teaching by simulation: Lessons learned from a complex patient care scenario. Nursing Education Perspectives, 27, 154-158.

Dunnington, R. (2010). High fidelity human patient simulation: Status of knowledge and pedagogical frameworks in nursing education. Unpublished dissertation, Ohio State University College of Education.

Feingold, C. E., Calaluce, M., \& Kallen, M. A. (2004). Computerized patient model and simulated clinical experiences: Evaluation with baccalaureate nursing students. Journal of Nursing Education, 43, 156-163.

Gliem, J., \& Gliem, R. (2003). Calculating, interpreting, and reporting Cronbach's alpha reliability coefficient for Likert-type scales. Paper presented at the 2003 Midwest Research to Practice Conference in Adult, Continuing, and Community Education. Columbus, $\mathrm{OH}$ : Ohio State University. Retrieved November 16, 2011, from https://scholarworks.iupui.edu/bitstream/handle/1805/344/Gliem $+\&+$ Gliem.pdf?sequence $=1$.
Jeffries, P. (2005). A framework for designing, implementing and evaluating simulations used as teaching strategies in nursing. Nursing Education Perspectives, 26, 96-103.

Jeffries, P. R., \& McNelis, A. M. (2010). Evaluation. In W. M. Nehring, \& F. R. Lashley (Eds.), High-fidelity patient simulation in nursing education (pp. 405-424). Boston, MA: Jones and Bartlett.

Jeffries, P. R., \& Rizzolo, M. A. (2006). Designing and implementing models for the innovation use of simulation to teach nursing care of ill adults and children: A national multi-site study. New York, NY: National League for Nursing. Retrieved November 16, 2011, from http://www.nln.org/research/LaerdalReport.pdf.

Johnson, S., Smith, P., \& Tucker, S. M. (1982). Response format of the Job Descriptive Index: Assessment of reliability and validity by the multitraitmultimethod matrix. Journal of Applied Psychology, 67, 500-505.

Kardong-Edgren, S., Adamson, K. A., \& Fitzgerald, C. (2010). A review of currently published evaluation instruments for human patient simulation. Clinical Simulation in Nursing, 6(1), e25-e35. doi: 10.1016/j.ecns.2009.08.004.

Komorita, S. S., \& Graham, W. K. (1965). Number of scale points and the reliability of scales. Educational and Psychological Measurement, 4, 987-995.

Lapkin, S., Levett-Jones, T., Bellchambers, H., \& Fernandez, R. (2010). Effectiveness of patient simulation manikins in teaching clinical reasoning skills to undergraduate nursing students: A systematic review. Clinical Simulation in Nursing, 6(6), e207-e222. doi: 10.1016/j.ecns.2010.05.005.

Lissitz, R. W., \& Green, S. B. (1975). Effect of the number of scale points on reliability: A Monte Carlo study. Journal of Applied Psychology, 60, 10-13.

Matell, M. G., \& Jacoby, J. (1972). Is there an optimal number of alternatives for Likert-scale items? Journal of Applied Psychology, 56, 506-509.

McCausland, L. L., Curran, C. C., \& Cataldi, P. (2004). Use of a human simulator for undergraduate nursing education. International Journal of Nursing Education Scholarship, 1(1), 1-17.

Mitchell, M. L., \& Jolley, J. M. (2010). Research design explained. Belmont, CA: Wadsworth.

Morgan, P. J., Pittini, R., Regeher, G., Marrs, C., \& Haley, M. F. (2007). Evaluating teamwork in a simulated obstetric environment. Anesthesiology, 106, 907-915.

Nehring, W. M. (2010). A synthesis of theory and nursing research using high-fidelity patient simulation. In W. M. Nehring, \& F. R. Lashley (Eds.), High-fidelity patient simulation in nursing education (pp. 27-56). Boston, MA: Jones and Bartlett.

Nehring, W., Lashley, F., \& Ellis, F. (2002). Critical incident nursing management using human patient simulators. Nursing Education Perspectives, 23, 129-132.

Nunnally, J. C., \& Bernstein, I. H. (1994). Psychometric theory (3rd ed.). New York, NY: McGraw-Hill.

Polit, D. F., \& Beck, C. T. (2008). Nursing research: Generating and assessing evidence for nursing practice (8th ed.). New York: J.B. Lippincott.

Polit, D. F., \& Hungler, B. P. (1995). Nursing research principles and methods (5th ed.). Philadelphia, PA: Lippincott.

Prion, S. (2008). A practical framework for evaluating the impact of clinical simulation experiences in prelicensure nursing education. Clinical Simulation in Nursing, 4(3), e69-e78. doi:10.1016/j.ecns.2008.08.002.

Sanford, P. G. (2010). Simulation in nursing education: A review of the research. Qualitative Report, 15(4), 1006-1011.

Scherer, Y. K., Bruce, S. A., \& Runkawatt, V. (2007). A comparison of clinical simulation and case study presentation on nurse practitioner students' knowledge and confidence in managing a cardiac event. International Journal of Nursing Education Scholarship, 4. article 22.

Schoening, A. M., Sittner, B. J., \& Todd, M. J. (2006). Simulated clinical experience: Nursing students' perceptions and the educators' role. Nurse Educator, 31, 253-258.

Scriven, M. (1996). Types of evaluation and types of evaluator. Evaluation Practice, 17(2), 151-161. 
Seropian, M. A., Brown, K., \& Gavilanes, J. S. (2004). An approach to simulation program development. Journal of Nursing Education, 43(4), 170-174.

Todd, M., Manz, J. A., Hawkins, K. S., Parsons, M. E., \& Hercinger, M. (2008). The development of a quantitative evaluation tool for simulations in nursing education. International Journal of Nursing Education Scholarship, 5(1), 1-17.

Trochim, W. K. (2006). Theory of reliability. Retrieved August 3, 2011, from http://www.socialresearchmethods.net/kb/reliablt.php. 